\title{
A ACESSIBILIDADE COMO INOVAÇÃO NA EDUCAÇÃO A DISTÂNCIA DE UMA REDE INTERNACIONAL DE ENSINO SUPERIOR A DISTÂNCIA
}

\author{
SÃO PAULO/SP MAIO/2018 \\ $\begin{array}{cc}\text { Soellyn Elene Bataliotti } & \text { - Laureate - sol.bataliotti@gmail.com } \\ \text { Gabriela Alias Rios } & \text { - IFSP - bihalias@gmail.com }\end{array}$ \\ Tipo: Investigação Científica (IC) \\ Natureza: Relatório Final de Pesquisa \\ Categoria: Suporte e Serviços \\ Setor Educacional: EDUCAÇÃO SUPERIOR
}

\begin{abstract}
RESUMO
O objetivo desta pesquisa é analisar as ações de acessibilidade possibilitadas por uma Rede Internacional de Ensino Superior com ofertas de cursos na modalidade a Distância. A pesquisa parte do princípio da necessidade do envolvimento da equipe em um processo de inclusão para que se possa transformar a aprendizagem em uma ação acessível e inovadora. Para tanto, serão analisados os sistemas de acesso ao Ambiente Virtual de Aprendizagem e as ações realizadas por orientação de coordenadores e efetivadas pelos professores para possibilitar um ambiente que permite $o$ acesso $e$ permanência de todos. A Rede Internacional analisada está presente em 29 países com cursos focados para a graduação, mestrado e doutorado, no Brasil os cursos de formação para o Ensino Superior são ofertados por nove instituições espalhadas pelo país com cursos nas modalidades presencial e a distância e tem como missão oferecer a educação a distância com qualidade, proporcionando o acesso de um número maior de pessoas, para uma aprendizagem inovadora. Dentre a modalidade a distância, o tipo de oferta de cursos alcança muitas regiões do país, assim a Rede Internacional tem como premissas além da qualidade no ensino, a ética, o foco no estudante e 0 desafio sempre com objetivos na excelência. Para isto é necessário o olhar atento a todas as necessidades dos estudantes de forma a incluí-los. Como resultado espera-se apresentar e elencar ações inclusivas, inovadoras e importantes que permitem o acesso e permanência de todos estudantes que procuram pela formação na modalidade da educação a distância.
\end{abstract}

Palavras-chave: Acessibilidade; Inovação; Ambiente Virtual de Aprendizagem; Educação Superior

AGRADECIMENTOS

AGRADECIMENTOS A ABED, POR OPORTUNIZAR MOMENTOS QUE VALORIZAM A MODALIDADE E A LAUREATE EAD POR INCENTIVAR NA PARTICIPAÇÃO DE FORMAÇÃO COMO ESTA E POR SE PREOCUPAR POR UMA EAD COM QUALIDADE. 


\section{Introdução}

A Educação a Distância (EaD) vem ganhando, ao longo dos anos, cada vez mais espaço no ensino brasileiro, o que tem possibilitado o acesso a formação de profissionais para diversos campos de atuação. O Censo do Ensino Superior do Instituto Nacional de Estudos e Pesquisas Educacionais Anísio Teixeira (INEP, 2015) demonstra a tendência de crescimento de cursos na modalidade a distância nos últimos anos, para formação de bacharel, de licenciados e de tecnológos no ano de 2015.

Dentre as vantagens da oferta da modalidade a distância Schlünzen Junior (2009, p. 14) destaca a importância das "alternativas para ultrapassar as dimensões geográficas, possibilitando que cidadãos de diferentes regiões tenham acesso a uma boa formação, com a construção de uma Universidade aberta, democrática e de qualidade." O referido autor reafirma que a educação a distância permite que pessoas de áreas mais remotas possam ter acesso a uma educação com qualidade, sem precisar se deslocar aos centros onde os cursos são oferecidos para estudar, o que no formato presencial este acesso estaria mais limitado.

Com um prognóstico favorável e a democratização do ensino é fato que há o crescimento da demanda, e nesta perspectiva não se pode ignorar que pessoas com deficiência também buscam acesso à formação, inclusive pela modalidades a distância. Porém é necessário citar que o histórico de acesso à educação para as pessoas com deficiência desde as escolas tradicionais sempre esteve caracterizado por uma luta de direitos, tendo em vista que os dados apresentados pelo Censo 2010 sobre o acesso à educação, pessoas com deficiência em geral, 14,2\% possuíam o fundamental completo, $17,7 \%$, o médio completo e $6,7 \%$ possuíam superior completo. A proporção denominada "não determinada" foi igual a 0,4\%. Em 2010, grande parte da população com deficiência não tem instrução e ensino fundamental completo, o que representa $61,1 \%$ das pessoas com deficiência (CENSO DEMOGRAFICO 2010, 2012).

Com o crescimento da oferta, temos no país diversas instituições de ensino que estão se adequando para alcançar o maior número de estudantes que antes não tinham acesso à educação. Dentre as instituições com a proposta de promover além do ensino presencial, como também o a distância há uma Rede Internacional Superior a Distância, presente em 29 países com cursos focados para a graduação, mestrado e doutorado, que no Brasil os cursos de formação para o Ensino Superior são ofertados por nove instituições espalhadas pelo país com cursos nas modalidades presencial, possível observar no mapa apresentado pela imagem 1. 
Imagem 1: Polos EaD pelo Brasil, Rede Internacional pesquisada

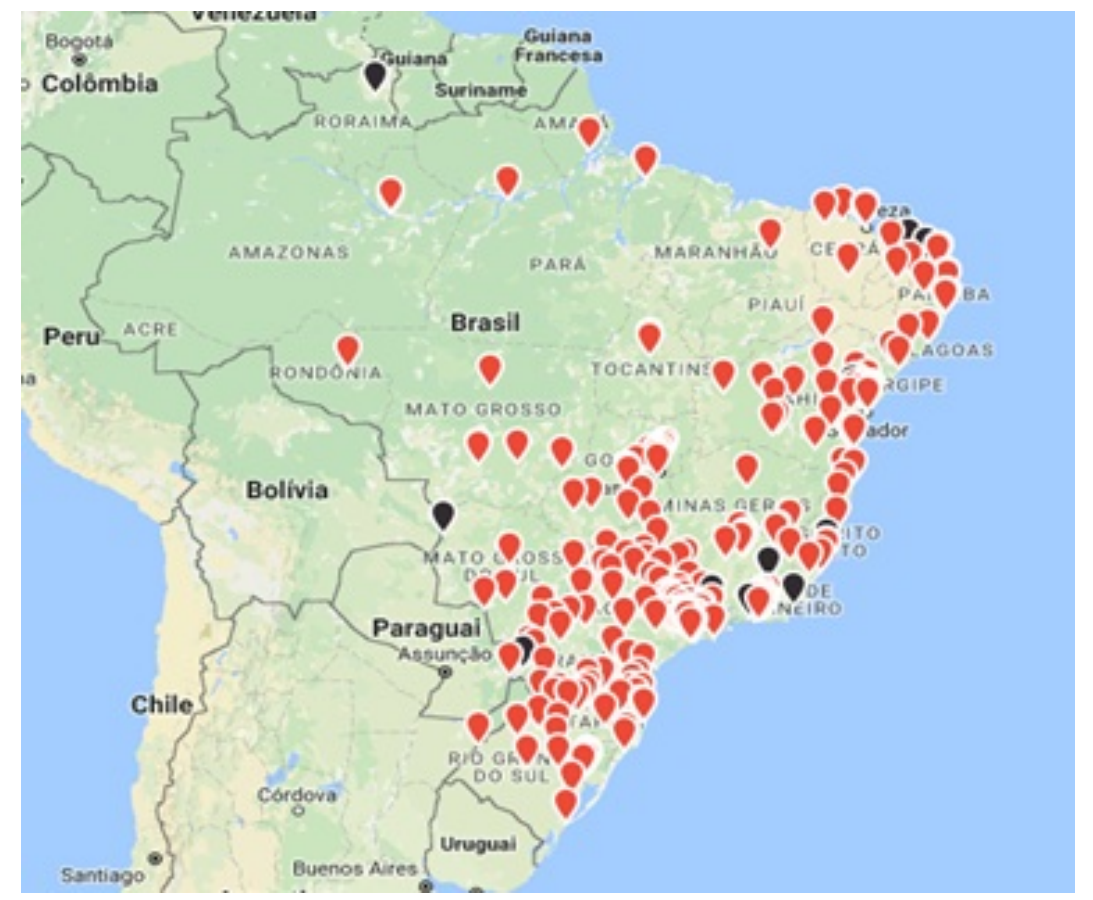

Fonte: Rede Internacional de Ensino.

Descrição: Imagem do mapa do Brasil contendo pontos vermelhos representativos de polos de graduação disponível com maior proporção nas regiões sul, sudeste e no litoral do nordeste e com menor proporção nas regiões centro-oeste e norte. Há pontos pretos que representam a pós-graduação um em cada região do Paraná, Minas Gerais, Rio de Janeiro, Espírito Santo, Mato Grosso do Sul, Bahia, Rio Grande do Norte e Roraima.

Dentre a proposta destacada pela instituição, tem como missão oferecer a educação a distância com qualidade, proporcionando o acesso de um número maior de pessoas, para uma aprendizagem inovadora. Dentre a modalidade a distância, o tipo de oferta de cursos alcança muitas regiões do país, assim a Rede Internacional tem como premissas além da qualidade no ensino, a ética, o foco no estudante e o desafio sempre com objetivos na excelência.

Por permitir o acesso a uma grande gama de alunos, é preciso oferecer cursos que tenham como pressuposto que os estudantes matriculados conseguirão estudar, sem prejuízo no acesso aos conteúdos por barreiras de ordem comunicacional e de usabilidade. Nesse sentido, faz-se necessário o planejamento de cursos que sejam acessíveis para as pessoas com deficiência.

Neste sentido, para que haja a inclusão do estudante são necessárias oportunizar um 
ambiente acessível que permita o acesso, a interação, compreensão e a permanência.

\section{Referencial Teórico}

Há para o uso da internet (requisito básico para a EaD) orientações e recomendações para oportunizar que todos tenham a mesma qualidade de acesso à web, no qual chamamos de acessibilidade.

\footnotetext{
Acessibilidade: condição para utilização, com segurança e autonomia, total ou assistida, dos espaços, mobiliários e equipamentos urbanos, das edificações, dos serviços de transporte e dos dispositivos, sistemas e meios de comunicação e informação, por pessoa portadora de deficiência ou com mobilidade reduzida (BRASIL, 2004, Art. 8).
}

Como um principal regulador de orientações para a acessibilidade temos o Word Wide Web Consortium (W3C) que testa, acompanha e sugere mudanças nos padrões para que haja a evolução da web, permitindo assim que programadores possam utilizar da expertise já indicada para que se crie Ambientes Virtuais que sejam acessível para todos.

Em nosso país a W3C Brasil que orienta os padrões de acessibilidade na internet e o Modelo de Acessibilidade em Governo Eletrônico (eMAG) que está alinhado as recomendações internacionais, mas estabelece padrões de comportamento acessível para sites governamentais e brasileiros (BRASIL, 2011).

Desta forma, elencamos itens para a acessibilidade segundo as orientações já existentes, disponibilizadas pelo W3C Brasil e eMAG.

\subsection{Acesso à internet pelo usuário;}

Segundo as orientações da W3C Brasil (s/a) é importante que além de oportunizar a acessibilidade em ambientes virtuais, o usuário deve certificar-se:

- Que possui um dispositivo computacional que possua os softwares adequados para acesso à internet;

- Que tenha um provedor de internet que permita o acesso contínuo a páginas na web;

\section{- 2.2. Acessibilidade na Web}

Segundo Brasil (2013; 2015) existe dimensões de acessibilidade, sendo elas: 
arquitetônica, atitudinal, pedagógica, de comunicação, digital, programática, instrumental e nos transportes.

Para a Educação a Distância atentamos as acessibilidades atitudinal (referente ao tratar, a como lidar com a pessoa e remover barreiras), a pedagógica (envolve a metodologia utilizada para lidar com o estudante, com dialogicidade, sem verborrogia), a de comunicação (a forma de comunicar-se com o outro, seja por fala, por escrita, por Libras, por braille) e a digital (o uso de programas adequados para o acesso digital, softwares ou de tecnologia assistiva) (BRASIL, 2013; 2015).

\subsection{Acessibilidade para o Ambiente Virtual de Aprendizagem}

Segundo o eMAG (BRASIL, 2011) alguns itens que devem ter cuidado, no qual pode ser evidenciado no Ambiente Virtual de Aprendizagem, são:

- Garantir que os objetos programados sejam acessíveis (utilizar as recomendações para o desenvolvimento e validá-los);

- Não ter uma página com atualização automática;

- Não utilizar limite de tempo;

- Não incluir situações de tela intermitente (efeitos visuais piscantes);

- Assegurar o controle do usuário sobre alterações temporais de conteúdos (conteúdos que "se movem", rolagens, movimentações em geral ou animações não devem ser disparadas automaticamente sem o controle do usuário);

- Identificar o idioma principal na página;

- Títulos informativos e descritivos na página;

- Disponibilizar informação sobre localização do usuário (migalha de pão);

- Descrever links claro e sucintamente (não utilizar o clique aqui);

- Utilizar a audiodescrição em imagens;

- Em tabelas utilizar: títulos e resumos; associar células de dados a células de cabeçalho;

- Disponibilizar explicações para siglas, abreviaturas, verbetes;

\subsection{Acessibilidade em materiais}

Sobre os materiais o eMAG (BRASIL, 2011) cita a importância.

- Fornecer acessibilidade para vídeos (audiodescrição; Libras e legenda);

- Fornecer alternativa para áudio (texto escrito);

- Fornecer acessibilidade em textos (audiodescrição); 
- Estabelecer ordem lógica de navegação nos materiais (principalmente textos);

\subsection{Acessibilidade pedagógica}

Na prática entre aluno e professor deve se ter algumas atenções quanto a acessibilidade pedagógica e a atitudinal, podemos citar:

- Escrever um texto com dialogicidade;

- Não utilizar verborrogia na comunicação;

Diante de algumas das orientações é preciso buscar garantir que o curso a distância seja acessível, desde o local em que são disponibilizados os materiais (a sala virtual), até os materiais didáticos digitais, bem como as comandas das atividades. De acordo com Brasil (2013), o material didático sem recursos de acessibilidade é um entrave para o acesso da pessoa com deficiência ao conteúdo do curso. Assim, na educação a distância, a acessibilidade é uma ação inovadora e importante para que possa garantir o acesso e a permanência dos estudantes matriculados, visto que grande parte desses cursos prevê a interação entre alunos e a realização de atividades.

Nessa direção, o trabalho tem como objetivo analisar as ações de acessibilidade possibilitadas por uma Rede Internacional de Ensino Superior com ofertas de cursos na modalidade a Distância.

\section{Metodologia}

Esta pesquisa é do tipo exploratória, visto que é investigada as ações de acessibilidade, esclarecendo ao leitor, por meio de exemplos práticos como é possível oportunizar a acessibilidade em um ambiente virtual de aprendizagem. (MOREIRA; CALEFFE, 2008).

As ações analisadas estão disponíveis no Ambiente Virtual de Aprendizgem do Blackboard Learn que é uma plataforma digital de tecnologias educacionais. Para a análise desta plataforma foi utilizado o aplicativo Lighthouse uma ferramenta automatizada de código aberto que verifica a qualidade de sistemas na Web, sendo executado na extensão do navegador do Google Chrome. Para os materiais foram dados os exemplos de ações de acessibilidade a partir de orientações pelos coordenadores e efetivadas por professores.

\section{Resultado e discussões}


O Ambiente Virtual de Aprendizagem Blackboard utilizado na Rede Internacional de Ensino Superior a Distância é simples, sem muita informação e de fácil acesso com leitores de tela, indicado com 100\% de acessibilidade pela Lighthouse, Imagem 2.

Imagem 2: Acessibilidade do Blackboard

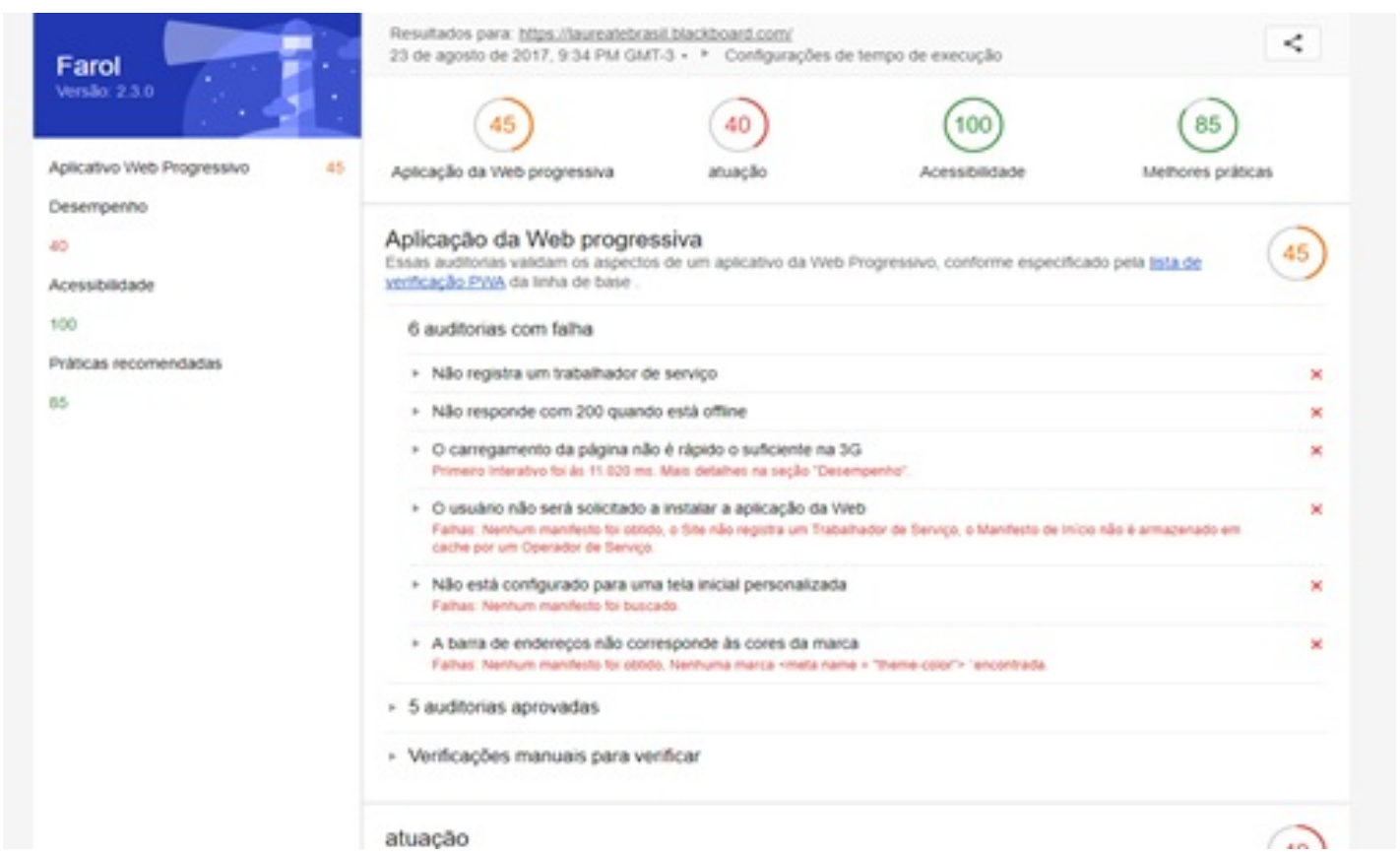

Fonte: Lighthouse

Descrição da imagem: Análise do site Lighthouse que analisa que o ambiente tem 45 aplicações da Web progressiva (apresentando-se na cor laranja, como razoável), com $40 \%$ de desempenho (apresentando-se na cor vermelha, com o desempenho abaixo do esperado), $100 \%$ de acessibilidade e 85 melhores práticas.

Para o acesso a da página da disciplina, como por exemplo "Fomação Inicial em EaD", é possível observar que o Lighthouse indica $97 \%$ de acessibilidade, informando que alguns itens da página como cor, plano de fundo, elementos com nomes compreensíveis, boa descrição dos conteúdos, contraste de cores é satisfatório, elementos bem estruturados, idioma válido, Tags usadas corretamente (Imagem 3).

Imagem 3: Pagina curso Formação Incial em EaD 


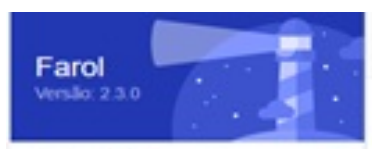

Aptcasvo Web Progessivo Devempento

25

Acessibatosde

97

Menoves Praticas

77

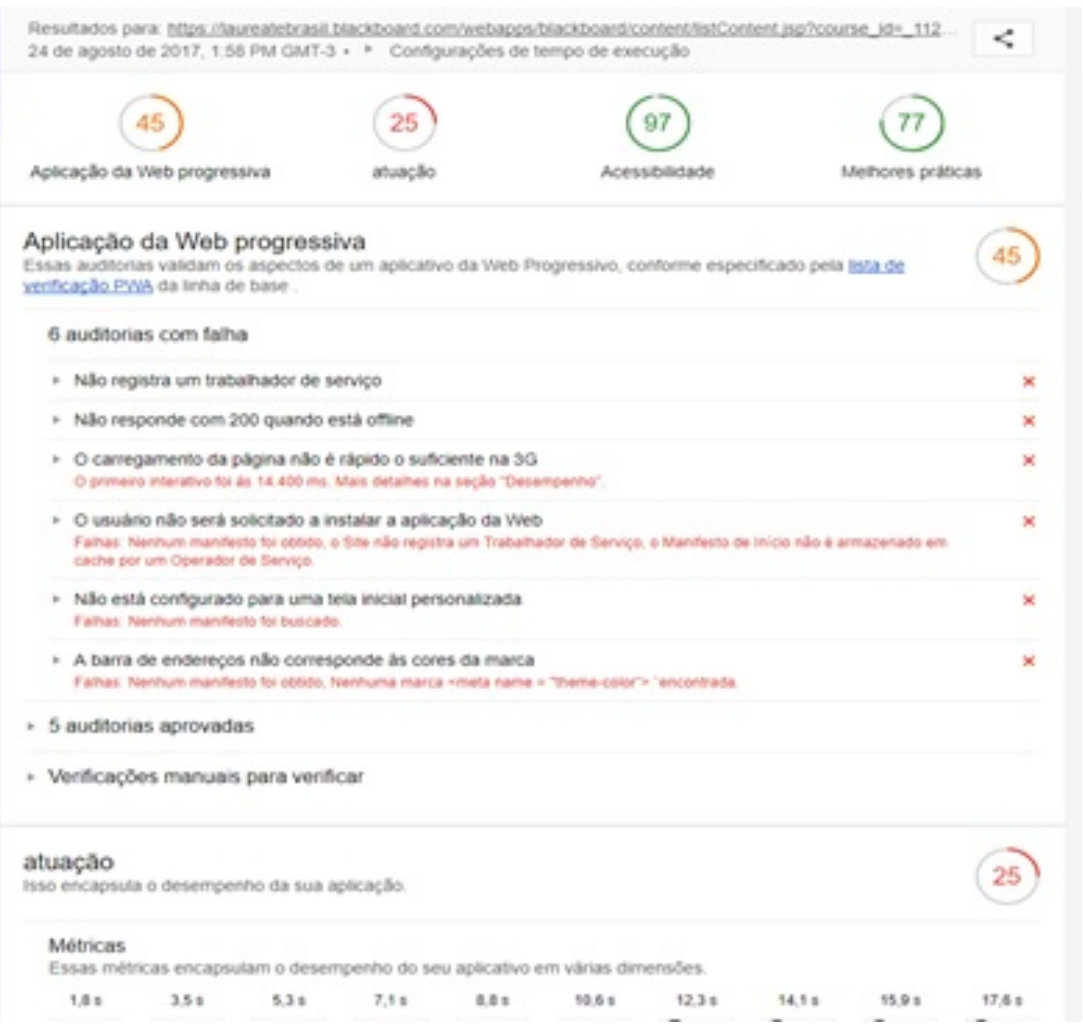

Fonte: Lighthouse

Descrição da imagem: Análise do site Lighthouse que analisa que o ambiente tem 45 aplicações da Web progressiva (apresentando-se na cor laranja, como razoável), com $25 \%$ de desempenho (apresentando-se na cor vermelha, com o desempenho abaixo do esperado), $97 \%$ de acessibilidade e 85 melhores práticas.

No entanto, em uma análise ergonômica do trabalho é possível observar elementos que faltam, como:

- Barra de acessibilidade, com elementos de contraste e zoom;

- Dimensão da letra, estando ela pequena;

- Audiodescrição dos logos e imagens;

- Título para o texto, pois há a utilização do "clique aqui" para acessar o texto.

Contudo, além o Ambiente Virtual de Aprendizagem há as ações pedagógicas orientadas por coordenadores e executadas por professores. Neste sentido, as ações são feitas por orientações via e-mails enviados a toda equipe, com correções na gramática para publicação de avisos, mensagens e sugestões de audiodescrição ao vincular imagens no ambiente como observado na imagem 4.

Imagem 4: Orientação de audiodescrição 
Sugestão de imagem para este aviso:

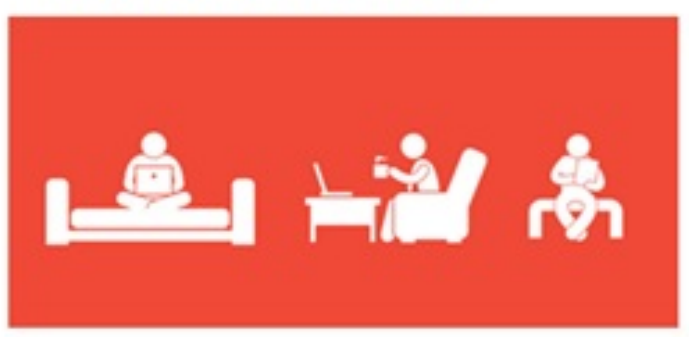

Descrição da imageml imagem contendo diferentes momentos em que um estudante interage com o ambiente virtual de aprendizagem, respectivamente: sentado na cama com o notebook, na sala e na praça.

Näo conseguiu visualizar a imagem? Acesse o mural de avisos da disciplina XOXXXXXXXXXXX em seu Ambiente Virtual de Aprendizagem Aviso sobre Webconferencia tinidade 2.

Fonte: email de vinculação interna da Rede Internacional

Descrição da imagem: Há uma figura com a seguinte orientação "sugestão de imagem para este aviso" e a sugestão é a seguinte mensagem "descrição da imagem: imagem contendo diferentes momentos em que um estudante interage com o ambiente virtual de aprendizagem, respectivamente: sentado na cama com o notebook, na sala e na praça. Não conseguiu visualizar a imagem? Acesse o mural de avisos da disciplina XXXXXXXXXXXX em seu Ambiente Virtual de Aprendizagem. Aviso sobre Webconferência Unidade 2."

Com o auxílio e a atenção da equipe, ações de acessibilidade vão acontecendo e o caminho de acesso para todos em uma educação inovadora vão sendo alcançados.

\section{Conclusão}

Para que se alcance uma educação inovadora e de qualidade deve-se ter claro que 'todos' deverão ter acesso. Com a possibilidade de maior alcance da EaD, felizmente, muitas pessoas de todos os cantos do país conseguem atualmente ter acesso a formação em graduação e pós-graduação, que não conseguiriam por outro modelo.

Neste sentido, o acesso de pessoas com deficiência também está ocorrendo e instituições de ensino superior devem estar preparadas, ou se preparando para receber estes estudantes. Contudo, o Ambiente Virtual de Aprendizagem utilizado pela Rede Internacional de Ensino Superior a Distância, o Blackboard, apresenta ser um ambiente acessível e amigável para programações e as ações de orientações pedagógicas feita pela equipe de coordenadores para os professores são ações de acessibilidade que surtem efeitos positivos para o acesso as orientações contidas nas disciplinas ofertadas. 
Pois, são ações simples, mas com um alcance satisfatório para aqueles que precisam de elementos acessíveis, podendo facilitar sua permanência no curso e a conclusão com êxito na sua formação profissional.

\section{Referências}

BRASIL. Instrumento de Avaliação de Cursos de Graduação presencial e a distância. Brasília, 2015.

BRASIL. Ministério da Educação. Referenciais de acessibilidade na EducaçãoSuperior e a avaliação in loco do Sistema Nacional de Avaliação da Educação Superior (SINAES). Brasília: Instituto Nacional de Estudos e Pesquisas Educacionais Anísio Teixeira, 2013.

BRASIL. Ministério do Planejamento, Orçamento e Gestão. Secretaria de Logística e Tecnologia da Informação. e-MAG Modelo de Acessibilidade em Governo Eletrônico/ Ministério do Planejamento, Orçamento e Gestão, Secretaria de Logística e Tecnologia da Informação. Brasília : MP, SLTI, 2011.

BRASIL. Ministério da Educação. Decreto no 5.296 de 2 de dezembro de 2004. Brasília, 2004.

CENSO DEMOGRÁFICO 2010. Características gerais da população, religião e pessoas com deficiência. Rio de Janeiro: IBGE, 2012.

INSTITUTO NACIONAL DE ESTUDOS E PESQUISAS EDUCACIONAIS ANÍSIO TEIXEIRA [INEP]. Censo da educação superior: 2011 - resumo técnico. Brasília: Instituto Nacional de Estudos e Pesquisas Educacionais Anísio Teixeira, 2013.

MOREIRA, H.; CALEFFE, L. G. Metodologia científica para o professor pesquisador. Rio de Janeiro: Lamparina, 2008.

SCHLÜNZEN JUNIOR, K. Educação a distância no Brasil: caminhos, políticas e perspectivas. ETD - Educação Temática Digital, Campinas, v. 10, n. 2, p. 16-36, jun. 2009.

W3C BRASIL. Cartilha acessibilidade na web. Disponível em: Acesso em 23 de ago. 2017. 